\title{
Calculation of rotation-vibration energy levels of the ammonia molecule based on an $a b$ initio potential energy surface
}

\author{
Oleg L. Polyansky \\ Department of Physics and Astronomy, \\ University College London, Gower Street, \\ London WC1E 6BT, United Kingdom and \\ Institute of Applied Physics, Russian Academy of Science, \\ Ulyanov Street 46, Nizhny Novgorod, Russia 603950* \\ Roman I. Ovsyannikov and Aleksandra A. Kyuberis \\ Institute of Applied Physics, Russian Academy of Science, \\ Ulyanov Street 46, Nizhny Novgorod, Russia 603950
}

Lorenzo Lodi, Jonathan Tennyson, Andrey Yachmenev, Sergei N. Yurchenko Department of Physics and Astronomy, University College London, Gower Street, London WC1E 6BT, United Kingdom

Nikolai F. Zobov Institute of Applied Physics, Russian Academy of Science, Ulyanov Street 46, Nizhny Novgorod, Russia 603950

(Dated: December 14, 2015) 


\begin{abstract}
An $a b$ initio potential energy surface (PES) for gas-phase ammonia $\mathrm{NH}_{3}$ has been computed using the methodology pioneered for water (Polyansky et al. J. Phys. Chem. A, 117, 9633 (2013)). Multireference configuration interaction calculations are perfomed at about 50000 points using the aug-cc-pCVQZ and aug-cc-pCV5Z basis sets and basis set extrapolation. Relativistic and adiabatic surfaces are also computed. The points are fitted to a suitable analytical form, producing the most accurate $a b$ initio PES for this molecule available. The rotation-vibration energy levels are computed using nuclear motion program TROVE in both linearized and curvilinear coordinates. Better convergence is obtained using curvilinear coordinates. Our results are used to assign the visible spectrum of ${ }^{14} \mathrm{NH}_{3}$ recorded by Coy and Lehmann (J. Chem. Phys., 84, 5239 (1988)). Rotation-vibration energy levels for the isotopologues $\mathrm{NH}_{2} \mathrm{D}, \mathrm{NHD}_{2}, \mathrm{ND}_{3}$ and ${ }^{15} \mathrm{NH}_{3}$ are also given. An $a b$ initio value for the dissociation energy of ${ }^{14} \mathrm{NH}_{3}$ is presented.
\end{abstract}

*Electronic address: o.polyansky@ucl.ac.uk 


\section{INTRODUCTION}

Ammonia is hazardous chemical, highly toxic for acquatic life, and its ever-increasing release into Earth's atmosphere has undesirable consequences [1]; monitoring its presence in the atmosphere is therefore a particularly important scientific objective. Remote sensing of spatially resolved atmospheric concentrations of ammonia requires reliable and extensive spectroscopic datasets and their deficiencies remain a significant source of error [2]. Another important area which requires spectroscopic data is astronomy; ammonia is thought to be the key spectroscopic signature of the coldest failed stars, so-called brown dwarfs [3, 4], and is probably also prominent in the atmospheres of exoplanetary gas giants [5]. All these applications require accurate spectroscopic data over extended frequency and temperatures ranges. This information is also required for the analysis and assignment of hot laboratory spectra $[6-9]$.

A review of experimental spectroscopic studies on ${ }^{14} \mathrm{NH}_{3}$ is given as part of a recent analysis [10], which provided the most extensive set of experimentally deduced energy levels for this system available to date. Unfortunately the available experimental data could only determine 30 vibrational band origins and only about 5000 rotation-vibrational (rovibrational) energy levels, so that any dataset which aims at completeness must rely on calculations; there is therefore a strong need for improved theoretical models of ammonia.

Very accurate ab initio calculations for the low-lying energy levels of $\mathrm{NH}_{3}$ were performed by Rajamäki et al $[11,12]$ using coupled-clusted (CC) methods. It is well known, though , that CC methods experience difficulties for calculations of highly excited rovibrational energy levels. That is why the ability to calculate very accurately ab initio surfaces using multireference configuration interaction (MRCI) methods is important, as this can provide an accurate global surface which can give good results for both low-lying and highly excited vibrational energy levels. Recently two high-accuracy ab initio studies of the rotationvibration energy levels of ammonia have been performed by Huang et al. [13-15] and by Yurchenko et al. [16-18] using high-quality, semi-empirical potential energy surfaces. In particular, Yurchenko et al. computed a linelist called BYTe including energy levels up to $18000 \mathrm{~cm}^{-1}$, containing over a billion transitions [17] and providing the most comprehensive coverage of spectra for ${ }^{14} \mathrm{NH}_{3}$. The energy levels of BYTe, more accurate below $5000 \mathrm{~cm}^{-1}$, already at $6000-7000 \mathrm{~cm}^{-1}$ differ from experiment by up to $5 \mathrm{~cm}^{-1}$, so that this database is 
not always able to provide so-called spectroscopic accuracy (i.e., line positions accurate to better than $1 \mathrm{~cm}^{-1}$ ) and consequently cannot address important unresolved issues such as the unassigned visible wavelength spectrum of ${ }^{14} \mathrm{NH}_{3}$ recorded by Coy and Lehmann three decades ago $[19,20]$. BYTe is also not appropriate for calculations of high-temperature spectra $(T>1200 \mathrm{~K})$ as such studies require energy levels up to at least up to $20000 \mathrm{~cm}^{-1}$ [21]. All these considerations provide key motivations for constructing a new, more accurate and more extensive ammonia PES.

This paper is organized as follows. In the section II the $a b$ initio method used is described, the choice of the grid points is given and the fitting procedure of these points to obtain analytical PES is presented. In section III we present a new theoretical value for

the dissociation energy $D_{0}$ of ammonia with an estimated uncertainty bar of $\pm 35 \mathrm{~cm}^{-1}$, which is much smaller than in all previous calculations; for example, in a recent study Marquardt et al. [22] report computed values for the dissociation energy with a scatter of about $1000 \mathrm{~cm}^{-1}$. Out theoretical value for $D_{0}$ is in disagreement with the corresponding experimental value, and some hypotheses on the origin of the observed discrepance are discussed. In the section IV we describe our nuclear motion calculations using the program TROVE $[23,24]$ in both linearised and curvilinear coordinates. In the section $\mathrm{V}$ the results of the rotation-vibrational energy levels of ammonia $\mathrm{NH}_{3}$ and its isotopologues are described and a comparison of these calculations with experimental data are presented; because of the much increased effort required for ammonia we could not afford for ammonia quite the same level of $a b$ initio theory as used for water [25] but nevertheless we were still able to compute accurate energy levels up to $18000 \mathrm{~cm}^{-1}$, covering all experimentally known levels. Section VI concludes this paper.

\section{CALCULATION OF THE $A B$ INITIO PES}

\section{A. Electronic structure calculations}

In the present study we apply the ab initio calculation scheme developed by us which was able to reproduce rovibrational energy levels of water with an accuracy of about $0.1 \mathrm{~cm}^{-1}$ [25]. The approach has recently been applied, with very good results, to the molecular ion $\mathrm{H}_{2} \mathrm{~F}^{+}$. [26]. This calculation scheme comprises 11 components and is expected to lead to very 
accurate PESs and to be applicable to small molecules made up by the atoms from the first and second periods of the periodic table ( $\mathrm{H}$ to $\mathrm{Ne}$ ). The various components are described in detail in ref. [26] and we present them here only summarily: 1) a main component based on MRCI [27] in the full-valence complete active space and the aug-cc-pCV6Z basis set [2830]; 2) a basis set correction based on extrapolation [31-33] using the aug-cc-pCV5Z basis sets; 3) a dense grid of geometries [26, 34-37]; 4) an electron correlation correction based on larger active spaces; 5) an adiabatic Born-Oppenheimer diagonal correction (BODC); 6) a scalar-relativistic correction $[38,39]$; 7) a higher-level relativistic correction based on the Dirac-Coulomb-Breit equation [40-42]; 8) a quantum electrodynamic correction (QED) [43-45]; 9) a non-adiabatic vibrational correction [25, 46-48]; 10) a non-adiabatic rotational correction $[47,49,50]$; 11) an off-diagonal spin-orbit correction [51-53].

In the following we will use the abbreviations acnz to indicate the aug-cc-pCVnZ basis sets and awcnz to indicate aug-cc-pwCVnZ ones [28-30].

As MRCI energies of points 1) and 4) should include size-extensivity corrections [27] (Davidson correction, $+\mathrm{Q}$, or Pople correction) or size-extensivity-corrected MRCI-type schemes such as the Averaged Coupled Pair Functional (ACPF) [54] or the averaged quadratic coupled-cluster (AQCC) [55] methods might be used instead; however, our recomendation is to use MRCI+Q, as other methods did not lead to better results in our tests with small molecules with up to five atoms. Internal-contraction approximation schemes $[56,57]$ may be used for MRCI.

At the moment it seems that, at least for the purposes of high-resolution spectroscopy of small molecules, MRCI-type methods provide the best accuracy; more advanced multireference coupled cluster approaches [58] have not yet been shown to produce superior results (see, e.g., table I of ref. [59]).

Ammonia, like water and $\mathrm{H}_{2} \mathrm{~F}^{+}$, is a ten-electron system but the presence of one more hydrogen atom renders it a substantially harder system from the point of view of ab initio calculations; the main reasons why this is so are: $i$ ) the PES depends on 6 internal coordinates instead of only 3, so many more single-point calculations are needed to sample it. ii) Each electronic-structure calculation is more expensive for ammonia than for water; in any given basis set the supplementary hydrogen atom increases the number of basis functions by about $30 \%$, and as electronic-structure methods scale with the number of basis functions $N$ at least as $N^{4}$ this modest increase in basis functions brings about a slowdown by a factor about 3 
with respect to water; furthermore, in multi-reference methods such as CASSCF (complete active space self-consistent field) and MRCI (multi-reference configuration interaction) [27] the size of the active space is also larger, resulting in a further significant slowdown for these methods. Finally, iii) because of the larger dimensionality the nuclear-motion problem is much more complicated and more difficult to treat; this complexity manifests itself with a number of novel properties not present in triatomic molecules, such as the splitting of its energy levels due to the umbrella motion. This makes the spectra of ammonia hard to analyse [19, 20, 60, 61].

We could not use all 11 components of our method in the present work for a variety of reasons. First of all tetratomic molecules requires about 50000 points, instead of about 2000 necessary for a triatomic calculation. Our computer resources did not allow us to calculate 50000 points using an aug-cc-pV6Z basis set, so we had to limit ourselves to using an augcc-pV5Z basis. In addition, we only used first-order relativistic corrections, without Breit or Gaunt terms. The QED correction, which is needed to achieve $0.1 \mathrm{~cm}^{-1}$ accuracy, was not deemed necessary for the present aim of about $1 \mathrm{~cm}^{-1}$ accuracy and was not included either. Non-adiabatic corrections were allowed for by the primitive change of nuclear masses to atomic masses. Certainly, future work aimed at achieving $0.1 \mathrm{~cm}^{-1}$ accuracy will have to consider all these corrections.

In conclusion we computed a main surface using the aug-cc-pwCV5Z basis set and MRCI in the full-valence reference space, comprising 8 electrons in 7 orbitals. The MRCI calculations used the Celani-Werner internal contraction scheme [57,62] and took about $50 \mathrm{~GB}$ of disk space, 3 GB of RAM and 7 hours of real time per geometry running on a single processor. A second surface computed with the same method but the smaller aug-cc-pwCQZ basis set was computed in order to perform basis-set extrapolation of the energies; each of these took about $10 \mathrm{~GB}$ of disk space and 45 minutes of run time on the same system. An electronic correlation correction surface was computed with the aug-cc-pwCQZ basis set and an extended reference space including two more orbitals; these calculations took about 1.5 hours per geometry. For the relativistic correction we used the expectation value of the MVD1 operator for the CASSCF wave functions in the aug-cc-pwCV5Z basis set. Overall our calculation required about 270000 CPU-hours ( $\approx 31$ CPU-years). 


\section{B. Fit to an analytic form}

In this study we used the grid of 51816 geometries from ref. [63], which was designed to include all important geometries covering the energy region below $20000 \mathrm{~cm}^{-1}$. However, as discussed below, only 22494 points were actually used in the final fit. To represent the $a b$ initio data sets analytically we use a form which has already been used in a series publications to represent the PES not only of $\mathrm{NH}_{3}$ [64] but also of other molecules and molecular ions $\mathrm{PH}_{3}, \mathrm{SbH}_{3}, \mathrm{BeH}_{3}, \mathrm{NH}_{3}^{+}, \mathrm{CH}_{3}^{+}, \mathrm{H}_{3} \mathrm{O}^{+}$[64-69].

$$
\begin{aligned}
V\left(\xi_{1}, \xi_{2}, \xi_{3}, \xi_{4 a}, \xi_{4 b} ; \sin \bar{\rho}\right)= & V_{\mathrm{e}}+V_{0}(\sin \bar{\rho})+\sum_{j} F_{j}(\sin \bar{\rho}) \xi_{j} \\
& +\sum_{j \leq k} F_{j k}(\sin \bar{\rho}) \xi_{j} \xi_{k} \\
& +\sum_{j \leq k \leq l} F_{j k l}(\sin \bar{\rho}) \xi_{j} \xi_{k} \xi_{l} \\
& +\sum_{j \leq k \leq l \leq m} F_{j k l m}(\sin \bar{\rho}) \xi_{j} \xi_{k} \xi_{l} \xi_{m} \\
& +\sum_{j \leq k \leq l \leq m \leq n} F_{j k l m n}(\sin \bar{\rho}) \xi_{j} \xi_{k} \xi_{l} \xi_{m} \xi_{n} \\
& +\sum_{j \leq k \leq l \leq m \leq n \leq o} F_{j k l m n o}(\sin \bar{\rho}) \xi_{j} \xi_{k} \xi_{l} \xi_{m} \xi_{n} \xi_{o}
\end{aligned}
$$

where

$$
\begin{aligned}
\xi_{k} & =1-\exp \left(-a\left(r_{k}-r_{\mathrm{e}}\right)\right), k=1,2,3, \\
\xi_{4 a} & =\frac{1}{\sqrt{6}}\left(2 \alpha_{1}-\alpha_{2}-\alpha_{3}\right), \\
\xi_{4 b} & =\frac{1}{\sqrt{2}}\left(\alpha_{2}-\alpha_{3}\right),
\end{aligned}
$$

$r_{\mathrm{e}}$ denotes the equilibrium value of $r_{k}$, and

$$
\sin \bar{\rho}=\frac{2}{\sqrt{3}} \sin \left[\left(\alpha_{1}+\alpha_{2}+\alpha_{3}\right) / 6\right]
$$

The pure inversion potential energy function in Eq. (1) is given by

$$
V_{0}(\sin \bar{\rho})=\sum_{s=1}^{8} f_{0}^{(s)}\left(\sin \rho_{e}-\sin \bar{\rho}\right)^{s},
$$


and the functions $F_{j k \ldots}(\sin \bar{\rho})$ are defined as

$$
F_{j k \ldots}(\sin \bar{\rho})=\sum_{s=0}^{N} f_{j k \ldots}^{(s)}\left(\sin \rho_{e}-\sin \bar{\rho}\right)^{s}
$$

where $\sin \rho_{e}$ is the equilibrium value of $\sin \bar{\rho}, a$ is a molecular parameter, and the quantities $f_{0}^{(s)}$ and $f_{j k \ldots}^{(s)}$ in Eqs. (6) and (7) are expansion coefficients. The summation limits in Eq. (7) are $N=6$ for $F_{j}(\sin \bar{\rho}), N=4$ for $F_{j k}(\sin \bar{\rho}), N=3$ for $F_{j k l}(\sin \bar{\rho}), N=2$ for $F_{j k l m}(\sin \bar{\rho}), F_{j k l m n}(\sin \bar{\rho})$, and $F_{j k l m n o}(\sin \bar{\rho})$. In total there are 301 symmetrically unique potential parameters $f_{j k \ldots}^{(s)}$. The symmetry relations between the parameters can be found in, for example, ref. [63].

The potential parameters $f_{0}^{(s)}$ and $f_{j k \ldots}^{(s)}$ were obtained by fitting to 22494 ab initio energies; 301 parameters were used to reproduce all these energies with a fitting error of $3.2 \mathrm{~cm}^{-1}$. The potential parameters together with a Fortran 90 program are given as supplementary material to this paper.

During fitting we assigned to each point an energy-dependent weight given by

$$
w=\frac{2}{1+e^{2 \cdot 10^{-4} \cdot E}}
$$

where $E$ is the energy in $\mathrm{cm}^{-1}$. The lowest point has a zero energy and hence a weight equal to unity. Some of ab initio points showed unsatisfactory accuracy, for example due to issues with convergence in our ab initio calculations. Such points could be detected in the fitting procedure by a simple test: the fitted analytic PES lies far away from inaccurate points. The accuracy of the final PES is systematically increased by excluding inaccurate points from the fitting procedure.

In this work we fitted directly the sum of basis-set extrapolated energies, relativistic corrections and higher-order correlation corrections; it was found beneficial to operate in this way as fitting the components separately resulted in larger fitting errors. We used initial 51816 unique geometries to produce ab initio points. But only 23725 points were calculated successfully (all QZ, 5Z energies; CAS and relativistic corrections have converged numerical values). However, the adiabatic correction was fitted separately as this made calculations for multiple isotopologues more convenient. 


\section{CALCULATION OF THE DISSOCIATION ENERGY}

In our previous theoretical calculations [70] we were able to produce a theoretical value for the dissociation energy of water, $D_{0}$, with an estimated error of $8 \mathrm{~cm}^{-1}$ and in perfect agreement with the very accurate experimental value; in this section we compute an accurate value of the dissociation energy $D_{0}$ of ammonia, an important quantity in thermochemistry. The lowest dissociation pathway for ammonia consists in stretching to infinity one of the hydrogen atoms, and we define the dissociation energy $D_{0}$ as

$$
D_{0}=E_{\mathrm{rvb}}\left(\mathrm{NH}_{2}\right)+E_{\mathrm{rvb}}(\mathrm{H})-E_{\mathrm{rvb}}\left(\mathrm{NH}_{3}\right)
$$

where the $E_{\text {rvb }}$ are the total (rovibronic) lowest energies of $\mathrm{NH}_{3}$ and of the dissociation fragments in their ground states. In the Born-Oppenheimer approximation the rovibronic energy are written as the sum of an electronic energy $E_{\text {el }}$ evaluated at the equilibrium geometry and a ro-vibrational energy $E_{\mathrm{vib}}$. As is custormary we define the potential well depth $D_{e}$ by an expression analogous to eq. (9) but involving the electronic energies of the various fragments evaluated at their equilibrium geometries:

$$
D_{e}=E_{\mathrm{el}}\left(\mathrm{NH}_{2}, \mathrm{eq}\right)+E_{\mathrm{el}}(\mathrm{H}, \mathrm{eq})-E_{\mathrm{el}}\left(\mathrm{NH}_{3}, \mathrm{eq}\right)
$$

and we also define the ro-vibrational zero-point energy (ZPE) of a system as the difference between the energy of the ro-vibrational ground state and the electronic energy evaluated at the equilibrium geometry. With these definitions we have that

$$
D_{0}=D_{e}+\mathrm{ZPE}\left(\mathrm{NH}_{2}\right)+\mathrm{ZPE}(\mathrm{H})-\mathrm{ZPE}\left(\mathrm{NH}_{3}\right)
$$

Experimentally one of the first accurate values for $D_{0}$ was reported by Bohme et al. [71] as $D_{0}=106.0 \pm 1.1 \mathrm{kcal} / \mathrm{mol}\left(37074 \pm 350 \mathrm{~cm}^{-1}\right)$; this value is in agreement with the later value by Gibson et al. [72] $D_{0}=106.7 \pm 0.3 \mathrm{kcal} / \mathrm{mol}\left(37300 \pm 100 \mathrm{~cm}^{-1}\right)$, which is widely reported in the literature. Qi et al. [73] reported in 1995 a value $D_{0}=4.97 \pm 0.05 \mathrm{eV}$ (40 100 $\pm 400 \mathrm{~cm}^{-1}$ ), considerably higher than previous values and in substantial disagreement with them. In 1996 Mordaunt et al. [74] reported much more accurate values for the dissociation energies of five ammonia isotopologues, reporting for the parent isotopologue ${ }^{14} \mathrm{NH}_{3} D_{0}=$ $37115 \pm 20 \mathrm{~cm}^{-1}$, in agreement with the value of Bohme et al. and in mild disagreement (by $2 \sigma$ ) with the one of Gibson et al.. 
TABLE I: Ab initio contributions to the dissociation energies of $\mathrm{NH}_{3}$. All values are in $\mathrm{cm}^{-1}$. Uncertainties, where available, are given in parenthesis. Signed contributions are additive corrections. Quantities A to F are nuclear-mass independent, all others are nuclear-mass dependent. See text for a full description of the contributions.

\begin{tabular}{|c|c|c|}
\hline label & Description & value unc. \\
\hline A & $\operatorname{CCSD}(\mathrm{T}) / \mathrm{ac}[56] \mathrm{z}$, all electron & $40344(21)$ \\
\hline $\mathrm{B}$ & CCSDTQP/wc2z, all electron & $+8(4)$ \\
\hline $\mathrm{C}$ & Geometry adjustment & $-135(8)$ \\
\hline $\mathrm{D}$ & Best non-relativistic $D_{e}[=\mathrm{A}+\mathrm{B}+\mathrm{C}]$ & $40218(23)$ \\
\hline $\mathrm{E}$ & Relativistic correction & $-32(3)$ \\
\hline $\mathbf{F}$ & Best mass-independent $D_{e}[=D+E]$ & $40188(23)$ \\
\hline G & Adiabatic correction (BODC), $\mathrm{NH}_{3}$ & $+60(10)$ \\
\hline $\mathbf{H}$ & Best mass-dependent $D_{e}[=F+G]$ & $40248(25)$ \\
\hline I & Zero point energy $\mathrm{NH}_{3}$ & $7433(1)$ \\
\hline $\mathrm{J}$ & Zero point energy $\mathrm{NH}_{2}[74]$ & $4005(25)$ \\
\hline $\mathrm{K}$ & Overall zero point energy contribution $[=\mathrm{J}-\mathrm{I}]$ & $-3428(25)$ \\
\hline $\mathbf{L}$ & Best theoretical $\mathrm{D}_{0}[=\mathbf{H}+\mathrm{K}]$ & $36820(35)$ \\
\hline M & Experimental $D_{0}[74]$ & $37115(20)$ \\
\hline $\mathrm{N}$ & Experiment - theory $[=\mathrm{M}-\mathrm{L}]$ & $295(40)$ \\
\hline
\end{tabular}

We computed an ab initio value for $D_{e}$ for ammonia by using high-order coupled cluster theory and eq. (10); because only calculation at equilibrium geometries are required the coupled cluster hierarchy is expected to converge very quickly and therefore we expect to produce a highly accurate reference value. We also compare the coupled cluster results with the MRCI ones. Because only one $\mathrm{NH}_{3}$ calculation is required, we could use basis sets which would be too expensive to use in a computation of the full surface. We present in table I a summary of the result and describe the details of the calculation in the following.

Contribution $A$ was computed using both for $\mathrm{NH}_{3}$ and for $\mathrm{NH}_{2}$ geometries with $r(\mathrm{~N}-$ $\mathrm{H})=1.01 \AA, \angle \mathrm{HNH}=108^{\circ}$. Calculation of the $\mathrm{NH}_{2} \tilde{X}^{2} B_{1}$ ground state used a restricted open-shell reference and the RHF-UCCSD(T) method [75-77]. The aug-cc-pCV5Z and aug- 
cc-pCV6Z energies were extrapolated using the formula $E_{n}=E_{\infty}+A /(n+1 / 2)^{4}$; the stated uncertainty is one half of the shift of the aug-cc-pCV6Z $D_{e}$ value to the basis-set extrapolated one.

Contribution B. A high-order coupled cluster correction (up to pentuple excitations [78, 79]) was computed using the geometries used for contribution $A$ above; the correction is computed as $D_{e}(\mathrm{CCSDTQP})-D_{e}(\mathrm{CCSD}(\mathrm{T}))$ using the cc-pwCVDZ basis set. The reported uncertainty is the absolute value of the difference between the shifts computed in the ccpwCVDZ and the cc-pVDZ basis sets. Correlation effects beyond CCSDTQP were estimated computing full configuration interaction (FCI) values of $D_{e}$ in the $6-31 \mathrm{G}$ and the cc-pVDZ basis set (frozen core calculations); the CCSDTQP $\rightarrow$ FCI correction amounts to only $+0.1 \mathrm{~cm}^{-1}$ using these basis sets and was neglected.

Contribution $C$. The geometries used in the main calculations (contributions A and B) are not exactly the equilibrium geometries neither for $\mathrm{NH}_{2}$ nor, to a smaller extent, for $\mathrm{NH}_{3}$, so we correct for this fact in this step. Using for $\mathrm{NH}_{3}$ the experimental equilibrium geometry $r(\mathrm{~N}-\mathrm{H})=1.012 \AA, \angle \mathrm{HNH}=106.7^{\circ}$ we get using $\operatorname{CCSD}(\mathrm{T}) /$ aug-cc-pCVQZ-DK (relativistic calculation using the Douglas-Kroll-Hess Hamiltonian to fourth order [80]) a contribution to $D_{e}$ of $+22 \mathrm{~cm}^{-1}$. Using for $\mathrm{NH}_{2}$ the experimental equilibrium geometry $r(\mathrm{~N}-\mathrm{H})=1.0254 \AA, \angle \mathrm{HNH}=102.85^{\circ}$ we get using CCSD $(\mathrm{T}) /$ aug-cc-pCV5Z-DK a contribution to $D_{e}$ of $-157 \mathrm{~cm}^{-1}$. The total contribution is therefore $+22-157=-135 \mathrm{~cm}^{-1}$. The error bar was established on the basis of comparison with calculations in smaller basis sets. Contribution E. Scalar relativistic correction were computed by expectation of the massvelocity one-electron Darwin operator (MVD1) and the MRCI wave function (full valence reference space) in the aug-cc-pCV5Z basis set; the geometries described in contribution $A$ above were used. The correction due to quantum electrodynamics was estimated by scaling on the one-electron Darwin term [45], amounts to $+2 \mathrm{~cm}^{-1}$ and was neglected. The error bar was established on the basis of comparisons with calculations in smaller basis sets and using the Douglas-Kroll-Hess Hamiltonian. The correction due to spin-orbit to $D_{e}$ is zero to first order of perturbation theory and is therefore negligible $\left(\ll 1 \mathrm{~cm}^{-1}\right)$.

Contribution G. The adiabatic correction (also known as the Born-Oppenheimer diagonal correction) was computed using CCSD in the cc-pwCTZ basis set (all electron calculations) and the program CFOUR $[81,82]$. The geometries used are the ones described in contribution $A$; the error bar was set on the basis of comparison with the Hartree-Fock value (which 
is $+52 \mathrm{~cm}^{-1}$ ) and of the CCSD/cc-pVDZ (frozen core) CCSD value (which is $+78 \mathrm{~cm}^{-1}$ ). Contribution I. The zero point energy of $\mathrm{NH}_{3}$ was obtained from the new PES produced in this work and was set to $7433(1) \mathrm{cm}^{-1}$; this value is in fair agreement with the one computed by Mordaunt et al. of $7415 \mathrm{~cm}^{-1}$ from experimental vibrational frequences and anharmonicity constants.

Contribution J. It is difficult to identify an accurate and reliable value for the zero point energy of the $\mathrm{NH}_{2}$ radical from the existing literature. Mordaunt et al. [74] use the value $4005 \mathrm{~cm}^{-1}$, which is in fair agreement with the one quoted by Demaison et al. [83] of $48.20 \mathrm{~kJ} / \mathrm{mol}\left(4029 \mathrm{~cm}^{-1}\right)$. We decided to use the value by Mordaunt et al. and assigned to it an error bar of $25 \mathrm{~cm}^{-1}$. This rather large error bar should also compensate from the fact that the ground state of $\mathrm{NH}_{2}$ has $J=1 / 2$ and not $J=0$ and because of this computing the zero point energy as $1 / 2$ of the sum of the harmonic frequences plus anharmonicity corrections (formula 4 of ref. [74]) is not a fully correct procedure.

As one can see from the values in table I there is a strong discrepancy (by more than $7 \sigma$ ) between our calculated value for $D_{0}$ and the experimentally-derived value from ref. [74];

We also computed values of $D_{e}$ using MRCI. For this method we can compute $D_{e}$ either by performing separate equilibrium calculations for $\mathrm{NH}_{3}$ and for $\mathrm{NH}_{2}$ and $\mathrm{H}$ as in the coupled cluster case or, alternatively, by performing a two calculation for $\mathrm{NH}_{3}$, one at equilibrium and one where one of the $\mathrm{N}-\mathrm{H}$ bonds is highly stretched. As MRCI is not a size consistent method we expect in principle different results for the two strategies; however, tests in the cc-pVDZ with the full valence reference space showed that the size extensivity error (i.e., the difference in $D_{e}$ between the two way of computing it) is only about $0.01 \mathrm{~cm}^{-1}$ both for MRCI and MRCI+Q energies and therefore completely negligible. We also tested the difference between energies computed using the Werner-Knowles internal contraction scheme [56] or the newer and faster Celani-Werner one [57, 62]; once again tests in the cc-pVDZ and the full reference space showed that the two variations produce energy curves in differing by less than $0.01 \mathrm{~cm}^{-1}$ along the whole stretching curve, so that we can assume both contraction scheme are equivalent in practice. With respect to the best non-relativistic coupled-cluster value (quantity D in table I) the MRCI value in the full valence reference space is $314 \mathrm{~cm}^{-1}$ lower while the Davidson-corrected MRCI+Q (fixed reference) is $23 \mathrm{~cm}^{-1}$ lower. Using a larger reference space with two extra orbitals the MRCI value is $295 \mathrm{~cm}^{-1}$ lower than the best coupled cluster based one and MRCI+Q is $53 \mathrm{~cm}^{-1}$ lower. Overall we consider the 
agreement of the MRCI+Q energies very good, especially in the full valence reference space. This observation implies than $\mathrm{MRCI}+\mathrm{Q}$ is capable of providing very high accuracy all the way up to dissociation.

\section{NUCLEAR MOTION CALCULATIONS}

Rotation-vibrational energy levels were calculated using the general, variational program TROVE $[23,24]$. In TROVE the ro-vibrational Hamiltonian is expressed in terms of internal valence coordinates as a Taylor series expansion around a non-rigid reference configuration and is represented explicitly on a grid. The expansion coefficients for kinetic energy operator (KEO) and the PES are obtained in a numerically exact fashion using automatic differentiation techniques. [24] In the present work, the kinetic and potential energy operators were expanded up to 8-th order in terms of the $\mathrm{N}-\mathrm{H}_{i}(i=1,2,3)$ stretching coordinates and of the symmetry-adapted bending coordinates

$$
\begin{gathered}
s_{4}=\frac{1}{\sqrt{6}}\left(2 \beta_{23}-\beta_{13}-\beta_{12}\right), \\
s_{5}=\frac{1}{\sqrt{2}}\left(\beta_{13}-\beta_{12}\right),
\end{gathered}
$$

where $\beta_{i j}$ is the $\angle\left(\mathrm{H}_{i}-\mathrm{N}-\mathrm{H}_{j}\right)$ bending angle projected on the plane perpendicular to the trisector vector. We choose to work with $s_{4}$ and $s_{5}$ given in terms of $\beta_{i j}$ rather than $\angle\left(\mathrm{H}_{i}-\mathrm{N}-\mathrm{H}_{j}\right)$ considering their relatively simple relations to the Cartesian coordinates of the atoms, which is highly desirable for the automatic procedure of constructing the KEO in TROVE. For expansion of the potential energy we employed Morse-type variables for the three stretching coordinates. The non-rigid reference configuration was defined by the umbrella-motion vibrational coordinate $\tau$ on a grid of 1000 points with displacements covering potential energies up to $40000 \mathrm{~cm}^{-1}$ above the minimum.

The general variational solution in TROVE involves several steps (basis set optimization, contraction, symmetrization) described in general elsewhere [23, 24] and in ref. [16] for $\mathrm{NH}_{3}$ in particular. The size of the total vibrational basis set is controlled by the polyad number $P$

$$
P=2\left(n_{\mathrm{NH}_{1}}+n_{\mathrm{NH}_{2}}+n_{\mathrm{NH}_{3}}\right)+n_{\mathrm{s}_{4}}+n_{\mathrm{s}_{5}}+\frac{n_{\tau}}{2},
$$

with $n_{i}$ denoting the quantum numbers of the corresponding primitive basis functions, which restricts the products of the primitive functions to those for which $P \leq P_{\max }$. In the present calculation we employed $P_{\max }=40$. 
The original implementation of TROVE performed calculations using rectilinear coordinates. However, during the course of this work a new version based on the use of curvilinear coordinates became available [84]. In particular, rectilinear coordinates, as illustrated by the first column of Table II, when used up to polyad number 28, which resulted in convergence of the highest experimentally known energy levels at about $18000 \mathrm{~cm}^{-1}$ to a discrepancy with experiment of about $100 \mathrm{~cm}^{-1}$. The use of curvilinear TROVE permitted the use of polyad numbers up to 40 and therefore allowed for much better convergence. The values of the parameters $r_{e q}$ and $\alpha_{e q}$ were determined during the fitting of ab initio points as $1.0106 \AA$ and $106.696^{\circ}$. However, we find better agreement with experiment if we change these values slightly to $1.0116 \AA$ and $106.719^{\circ}$. The calculated energy levels in Table II were obtained with these changed values.

To assess the accuracy of the variational setup employed in this study we performed calculations with basis sets of different sizes. Figure 1 plots the mean absolute differences between energies calculated with polyad number $P_{\max }$ and $\left(P_{\max }-4\right)$ in energy intervals of $2000 \mathrm{~cm}^{-1}$. All states with the energies below $20000 \mathrm{~cm}^{-1}$ and an absolute value of the leading coefficient in the wave function larger than 0.5 were selected for the plot, resulting in about 1200 in number. Gradual increase of the basis set improves the accuracy by about one order of magnitude for energies below $14000 \mathrm{~cm}^{-1}$, while for higher energies the curves on Fig. 1 show almost the same convergence rates for all states up to $20000 \mathrm{~cm}^{-1}$. This is due to the heavy mixing of states at higher energies, so that only few of them passed the threshold for the leading coefficient and were considered in the plot, fictitiously lowering the average errors. By extrapolating the convergence pattern between 6000 and $14000 \mathrm{~cm}^{-1}$ to higher energies it can be seen that to obtain an accuracy of $1 \mathrm{~cm}^{-1}$ for all energy levels below $20000 \mathrm{~cm}^{-1}$ the basis set must be extended to at least $P_{\max }=48$.

\section{ROVIBRATIONAL ENERGY LEVELS OF $\mathrm{NH}_{3}$ AND ISOTOPOLOGUES}

In the table II experimental energy levels of ammonia molecule, as well as the detuning calculated from the experimental energies at different values of the parameter $P_{\max }$ are presented. Comparing detuning of the same energy at different values of $P_{\max }$ it is possible to assess convergence properties with basis extention. Calculations $P_{\max }=28$ was carried out with the linearized coordinates, while calculations with $P_{\max }>28$ was performed with 


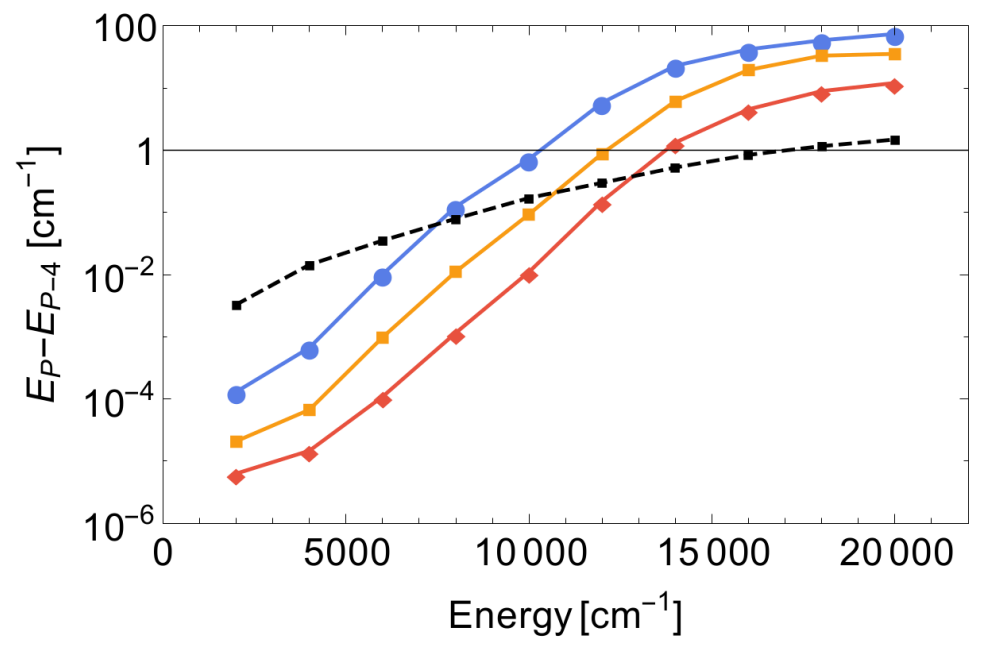

FIG. 1: Basis set convergence of $\mathrm{NH}_{3}$ vibrational energy levels. The mean absolute energy differences $\left|E\left(P_{\max }\right)-E\left(P_{\max }-4\right)\right|$ are drawn in each energy interval $\left(2000 \mathrm{~cm}^{-1}\right.$ wide $)$ for three basis sets truncated at polyad numbers $P_{\max }=32,36$, and 40 in blue circles, orange squares, and red diamonds, respectively. For KEO series truncation errors, the respective differences for $N_{\mathrm{KEO}}=8$ and 6 are drawn as a black dashed line.

curvilinear coordinates.

Table III compares the results of $J=0$ calculations on ${ }^{14} \mathrm{NH}_{3}$ with the $J=0$ energy levels, obtained in Ref. [10] using the MARVEL procedure [85, 86]. The table substantiates our claim that we can reproduce the energy levels of $\mathrm{NH}_{3}$ to within $1 \mathrm{~cm}^{-1}$.

Table IV presents a comparison of our calculations with the measured energy levels of highly-excited stretching $\left(v_{2}=0\right)$ levels up to $18000 \mathrm{~cm}^{-1}$. These energies were obtained by Coy and Lehmann quite some time ago [19, 20], but there are previous no attempts to reproduce these levels from the first principles. Comparing these results with the ones for water computed at the same level of theory, see Table $\mathrm{V}$, one finds that the results are very similar. To obtain calculated water levels we like in the case with ammonia slightly changed the equilibrium parameters.

The correctness of the calculated levels of table IV (and of the labelling of the experimental energy levels in table II) was also confirmed by calculations of vibrational band intensities, shown in table VI. In experiment usually the strongest bands are visible. Therefore, quantum numbers of the strongest lines from table VI were taken, corresponding to 
TABLE II: Convergence of the highly excited levels of $\mathrm{NH}_{3}$ for different polyad number $P_{\max }$ and rectilinear ('rect') or curvilinear ('curv') coordinates. The column labelled 'obs' are experimental energy levels from ref.[20], the other columns are differences to calculated values. All energies are in $\mathrm{cm}^{-1}$.

\begin{tabular}{|c|c|c|c|c|c|}
\hline$P_{\max }=$ & 28 & 28 & 32 & 36 & 40 \\
\hline coordinates $=$ & rect & curv & curv & curv & curv \\
\hline \multicolumn{6}{|l|}{ Label } \\
\hline $\mathrm{A}_{1}^{\prime}$ & 6798.47 & 6798.44 & 6798.33 & 6798.30 & 6798.30 \\
\hline $\mathrm{A}_{2}^{\prime \prime}$ & 6796.86 & 6796.74 & 6796.68 & 6796.67 & 6796.67 \\
\hline $\mathrm{E}^{\prime \prime}$ & 6611.54 & 6610.79 & 6611.08 & 6610.67 & 6610.67 \\
\hline $\mathrm{E}^{\prime}$ & 6610.16 & 6609.85 & 6609.99 & 6610.67 & 6609.73 \\
\hline $\mathrm{E}^{\prime}$ & 6666.60 & 6666.45 & 6666.44 & 6666.38 & 6666.37 \\
\hline $\mathrm{E}^{\prime \prime}$ & 6679.58 & 6679.24 & 6679.04 & 6679.16 & 6679.16 \\
\hline $\mathrm{E}^{\prime}$ & 6678.66 & 6678.55 & 6678.27 & 6678.47 & 6678.47 \\
\hline $\mathrm{E}^{\prime \prime}$ & 6852.22 & 6851.99 & 6851.97 & 6851.94 & 6851.94 \\
\hline $\mathrm{E}^{\prime}$ & 6851.69 & 6851.56 & 6851.52 & 6851.51 & 6851.51 \\
\hline $\mathrm{E}^{\prime \prime}$ & 9749.77 & 9742.15 & 9744.66 & 9741.41 & 9741.40 \\
\hline $\mathrm{E}^{\prime} \mathrm{E}(\mathrm{s})$ & 9744.54 & 9740.32 & 9742.14 & 9739.86 & 9739.86 \\
\hline $\mathrm{E}^{\prime \prime}$ & 9702.32 & 9693.64 & 9697.24 & 9692.63 & 9692.62 \\
\hline $\mathrm{E}^{\prime} \mathrm{E}(\mathrm{s})$ & 9695.72 & 9692.37 & 9690.40 & 9691.72 & 9691.71 \\
\hline $\mathrm{E}^{\prime \prime}$ & 9656.15 & 9645.99 & 9649.91 & 9644.91 & 9644.90 \\
\hline $\mathrm{E}^{\prime} \mathrm{E}(\mathrm{a})$ & 9648.85 & 9642.40 & 9645.10 & 9641.72 & 9641.72 \\
\hline $\mathrm{E}^{\prime \prime}$ & 12664.59 & 12651.93 & 12652.12 & 12627.62 & 12627.56 \\
\hline $\mathrm{E}^{\prime} \mathrm{E}(\mathrm{av})$ & 12718.80 & 12683.14 & 12697.96 & 12676.55 & 12676.39 \\
\hline $\mathrm{A}_{2}^{\prime \prime}$ & 15507.56 & 15527.04 & 15467.51 & 15453.04 & 15446.91 \\
\hline $\mathrm{A}_{1}^{\prime}$ & 15487.20 & 15497.11 & 15466.35 & 15459.60 & 15458.98 \\
\hline $\mathrm{E}^{\prime \prime}$ & 15507.72 & 15527.15 & 15467.76 & 15456.63 & 15455.64 \\
\hline $\mathrm{E}^{\prime}$ & 15487.51 & 15499.76 & 15466.82 & 15458.79 & 15458.11 \\
\hline $\mathrm{A}_{2}^{\prime \prime}$ & 18292.10 & 18404.01 & 18184.72 & 18127.73 & 18123.49 \\
\hline $\mathrm{A}_{1}^{\prime}$ & 18262.25 & 18351.99 & 18145.72 & 18115.67 & 18115.57 \\
\hline $\mathrm{E}^{\prime \prime}$ & 18294.78 & 18410.40 & 18184.07 & 18131.45 & 18122.74 \\
\hline $\mathrm{E}^{\prime}$ & 18265.52 & 18349.18 & 18145.34 & 18118.70 & 18119.42 \\
\hline
\end{tabular}


transitions from the ground vibrational state to the energy levels with strong stretch excitation. These calculated levels (and quantum number) were substituted into tables II and IV.

Further comparison of the accuracy of the present calculations with the highly excited energy levels of $\mathrm{NH}_{3}$ became possible while during the course of this work thanks to new assignments of highly excited ammonia states close to $8000 \mathrm{~cm}^{-1}$ [87]. In particular, the band origins of 5 highly excited vibrational states of ammonia have been determined from the new analysis of experimental data [87], see Table XI. As could be seen from the table, 4 out of five presented highly excited band origins are reproduced by our ab initio calculations within $2 \mathrm{~cm}^{-1}$ which is more accurate even, than the results of the semiempirical predictions taken from the linelist BYTe [17]. It confirms once more the accuracy of our PES and its ability to caluclate highly excited vibrational states of ammonia molecule.

Predicted energy levels for isotopically substituted $\mathrm{NH}_{3}$ were also computed. Results for $\mathrm{NH}_{2} \mathrm{D}, \mathrm{NHD}_{2}$ and $\mathrm{ND}_{3}$ are presented in tables VII, VIII and IX respectively. All isotopologues calculations were made with $P_{\max }=28$ and linearized TROVE coordinates.

TABLE III: Comparison of calculated $\left(P_{\max }=40\right)$ and experimental energy levels of ammonia [10] in $\mathrm{cm}^{-1}$.

\begin{tabular}{cccccccccccc}
\hline \hline$v_{1}$ & $v_{2}$ & $v_{3}$ & $v_{4}$ & $L_{3}$ & $L_{4}$ & $\mathrm{~L} i$ & $\mathrm{~s}$ & & & & \\
0 & & & \\
0 & 0 & 0 & 0 & 0 & 0 & $0-$ & $\mathrm{A}_{2}^{\prime \prime}$ & 0.79 & 0.03 & 0.01 & 0.00 \\
0 & 1 & 0 & 0 & 0 & 0 & $0-$ & $\mathrm{A}_{2}^{\prime \prime}$ & 968.12 & -3.69 & -0.38 & -0.01 \\
0 & 0 & 0 & 1 & 0 & 1 & $1+$ & $\mathrm{E}^{\prime}$ & 1626.27 & -1.36 & 0.09 & 0.06 \\
0 & 0 & 0 & 1 & 0 & 1 & $1-$ & $\mathrm{E}^{\prime \prime}$ & 1627.37 & -1.31 & 0.11 & 0.07 \\
0 & 2 & 0 & 0 & 0 & 0 & $0-$ & $\mathrm{A}_{2}^{\prime \prime}$ & 1882.18 & -5.67 & -0.44 & -0.37 \\
0 & 1 & 0 & 1 & 0 & 1 & $1+$ & $\mathrm{E}^{\prime}$ & 2540.52 & -7.14 & -1.13 & 0.22 \\
0 & 1 & 0 & 1 & 0 & 1 & $1-$ & $\mathrm{E}^{\prime \prime}$ & 2586.13 & -5.38 & -0.62 & 0.05 \\
0 & 3 & 0 & 0 & 0 & 0 & $0-$ & $\mathrm{A}_{2}^{\prime \prime}$ & 2895.52 & -5.64 & -0.21 & -0.07 \\
0 & 0 & 0 & 2 & 0 & 0 & $0-$ & $\mathrm{A}_{2}^{\prime \prime}$ & 3217.59 & -2.81 & -0.06 & -0.69 \\
0 & 0 & 0 & 2 & 0 & 2 & $2+$ & $\mathrm{E}^{\prime}$ & 3240.16 & -3.06 & -0.19 & -0.45 \\
0 & 0 & 0 & 2 & 0 & 2 & $2-$ & $\mathrm{E}^{\prime \prime}$ & 3241.60 & -3.10 & -0.17 & -0.43 \\
1 & 0 & 0 & 0 & 0 & 0 & $0-$ & $\mathrm{A}_{2}^{\prime \prime}$ & 3337.10 & -1.64 & -1.50 & -1.77
\end{tabular}




\begin{tabular}{|c|c|c|c|c|c|c|c|c|c|c|}
\hline 0 & 0 & 1 & 0 & 1 & 0 & $1+\mathrm{E}^{\prime}$ & 3443.63 & 0.03 & -0.50 & 0.27 \\
\hline 0 & 0 & 1 & 0 & 1 & 0 & $1-E^{\prime \prime}$ & 3443.99 & 0.02 & -0.50 & 0.28 \\
\hline 1 & 1 & 0 & 0 & 0 & 0 & $0-\mathrm{A}_{2}^{\prime \prime}$ & 4320.03 & -5.36 & -1.99 & -0.19 \\
\hline 0 & 1 & 1 & 0 & 1 & 0 & $1+\mathrm{E}^{\prime}$ & 4416.92 & -4.31 & -0.92 & -2.27 \\
\hline 0 & 1 & 1 & 0 & 1 & 0 & $1-\mathrm{E}^{\prime \prime}$ & 4435.45 & -3.63 & -0.82 & -2.36 \\
\hline 1 & 0 & 0 & 1 & 0 & 1 & $1+E^{\prime}$ & 4955.76 & -3.01 & -1.45 & -3.79 \\
\hline 1 & 0 & 0 : & 2 & 0 & 2 & $2+\mathrm{E}^{\prime}$ & 6556.42 & -4.71 & -1.94 & -6.52 \\
\hline 1 & 0 & 02 & 2 & 0 & 2 & $2-\quad \mathrm{E}^{\prime \prime}$ & 6557.93 & -4.97 & -1.88 & -6.75 \\
\hline 1 & 0 & 1 & 0 & 1 & 0 & $1+E^{\prime}$ & 6608.82 & -2.44 & -1.02 & -6.05 \\
\hline 1 & 0 & 1 & 0 & 1 & 0 & $1-\mathrm{E}^{\prime \prime}$ & 6609.75 & -2.81 & -1.02 & -6.18 \\
\hline 0 & 0 & 1 & 2 & 1 & 2 & $1+\mathrm{E}^{\prime}$ & 6677.43 & -1.85 & -1.11 & \\
\hline 0 & 0 & 12 & 2 & 1 & 2 & $1-E^{\prime \prime}$ & 6678.31 & -1.89 & -0.92 & \\
\hline 0 & 2 & 0 : & 3 & 0 & 1 & $1-\mathrm{E}^{\prime \prime}$ & 6678.93 & -15.53 & -2.48 & \\
\hline 0 & 0 & 2 & 0 & 2 & 0 & $2 \quad \mathrm{E}^{\prime}$ & 6850.24 & -0.45 & -1.32 & 2.52 \\
\hline 0 & 0 & 2 & 0 & 2 & 0 & $2 \quad \mathrm{E}^{\prime \prime}$ & 6850.65 & -0.47 & -1.33 & 2.53 \\
\hline 0 & 1 & 0 & 0 & 0 & 0 & $0+\mathrm{A}_{1}^{\prime}$ & 932.40 & -5.01 & -0.64 & 2.52 \\
\hline 0 & 2 & 0 & 0 & 0 & 0 & $0+\mathrm{A}_{1}^{\prime}$ & 1597.50 & -9.60 & -1.12 & 2.53 \\
\hline 0 & 3 & 0 & 0 & 0 & 0 & $0+\mathrm{A}_{1}^{\prime}$ & 2384.20 & -6.46 & -0.41 & \\
\hline 0 & 0 & 0 & 2 & 0 & 0 & $0+\mathrm{A}_{1}^{\prime}$ & 3216.00 & -2.69 & -0.04 & 0.17 \\
\hline 1 & 0 & 0 & 0 & 0 & 0 & $0+\mathrm{A}_{1}^{\prime}$ & 3336.10 & -1.67 & -1.52 & -0.41 \\
\hline 0 & 4 & 0 & 0 & 0 & 0 & $0+\mathrm{A}_{1}^{\prime}$ & 3462.50 & -5.54 & -0.02 & -1.22 \\
\hline 0 & 2 & 0 & 1 & 0 & 1 & $1-\mathrm{E}^{\prime \prime}$ & 3502.10 & -7.93 & -1.39 & -0.61 \\
\hline 0 & 1 & 0 & 2 & 0 & 0 & $0+\mathrm{A}_{1}^{\prime}$ & 4115.60 & -10.10 & -1.92 & -4.00 \\
\hline 0 & 1 & 0 & 2 & 0 & 2 & $2+\mathrm{E}^{\prime}$ & 4135.90 & -9.95 & -1.95 & 1.65 \\
\hline 0 & 1 & 0 & 2 & 0 & 0 & $0-\mathrm{A}_{2}^{\prime \prime}$ & 4173.30 & -7.33 & -0.79 & \\
\hline 0 & 1 & 0 & 2 & 0 & 2 & $2-\quad E^{\prime \prime}$ & 4193.10 & -7.51 & -1.08 & -0.39 \\
\hline 1 & 1 & 0 & 0 & 0 & 0 & $0+\mathrm{A}_{1}^{\prime}$ & 4294.50 & -6.20 & -2.16 & -0.43 \\
\hline 0 & 2 & 0 & 2 & 0 & 0 & $0+\mathrm{A}_{1}^{\prime}$ & 4754.30 & -17.61 & -5.83 & -0.30 \\
\hline 0 & 0 & 0 & 3 & 0 & 1 & $1+\mathrm{E}^{\prime \prime}$ & 4802.40 & -4.14 & 0.88 & -0.44 \\
\hline
\end{tabular}




\begin{tabular}{|c|c|c|c|c|c|c|c|c|c|c|}
\hline & 0 & 0 & 1 & 0 & 1 & $1-\mathrm{E}^{\prime \prime}$ & 4956.90 & -3.02 & -1.44 & 3.08 \\
\hline 1 & 2 & 0 & 0 & 0 & 0 & $0+\mathrm{A}_{1}^{\prime}$ & 5002.90 & -8.52 & 0.32 & \\
\hline 0 & 0 & 1 & 1 & 1 & 1 & $0+\mathrm{A}_{2}^{\prime}$ & 5051.40 & -1.57 & -0.58 & \\
\hline 0 & 0 & 1 & 1 & 1 & 1 & $0-\mathrm{A}_{1}^{\prime \prime}$ & 5052.10 & -1.49 & -0.48 & -4.00 \\
\hline 0 & 2 & 0 & 2 & 0 & 0 & $\begin{array}{ll}0 & \mathrm{~A}_{2}^{\prime \prime}\end{array}$ & 5092.60 & -11.21 & -2.61 & \\
\hline 0 & 2 & 0 & 2 & 0 & 2 & $2-\mathrm{E}^{\prime \prime}$ & 5112.80 & -10.87 & -2.45 & -0.71 \\
\hline 0 & 2 & 1 & 0 & 1 & 0 & $1+\mathrm{E}^{\prime}$ & 5146.34 & -8.38 & 0.18 & -0.57 \\
\hline 0 & 2 & 1 & 0 & 1 & 0 & $1-E^{\prime \prime}$ & 5352.80 & -6.39 & -1.10 & \\
\hline 0 & 2 & 0 & 3 & 0 & 1 & $1+E^{\prime}$ & 6310.30 & -22.00 & -5.43 & \\
\hline 2 & 0 & 0 & 0 & 0 & 0 & $0+\mathrm{A}_{1}^{\prime}$ & 6514.10 & -9.25 & -7.20 & \\
\hline 1 & 0 & 0 & 2 & 0 & 0 & $0+\mathrm{A}_{1}^{\prime}$ & 6648.20 & -5.86 & -3.68 & \\
\hline 1 & 0 & 0 & 2 & 0 & 0 & $0-\quad \mathrm{A}_{2}^{\prime \prime}$ & 6649.80 & -5.79 & -3.21 & \\
\hline 0 & 0 & 1 & 2 & 1 & 0 & $0+\mathrm{A}_{2}^{\prime}$ & 6651.40 & -2.82 & -0.26 & \\
\hline 0 & 0 & 1 & 2 & 1 & 0 & $0-\mathrm{A}_{1}^{\prime \prime}$ & 6652.60 & -2.92 & 0.09 & \\
\hline 0 & 0 & 2 & 0 & 0 & 0 & $0 \quad \mathrm{~A}_{2}^{\prime \prime}$ & 6792.00 & -3.98 & -4.73 & \\
\hline 0 & 0 & 2 & 0 & 0 & 0 & $0 \quad \mathrm{~A}_{1}^{\prime}$ & 6793.10 & -7.71 & -5.27 & \\
\hline
\end{tabular}

$a$ This work based on the $a b$ initio equilibrium geometry.

$b$ This work using shifted equilbrium geometry.

${ }^{c}$ Computed by Marquardt et al [22] using an empirically adjusted potential [89].

TABLE IV: Comparison of the observed $v_{2}=0$ high energy levels of ammonia (in $\mathrm{cm}^{-1}$ ) calculated in this work and due to Lehmann and Coy [20]; the second, non-standard symmetry labels are due to Lehmann and Coy.

\begin{tabular}{llc}
\hline \hline Sym. & obs. & obs.-calc. $($ this work) \\
\hline $\mathrm{E}^{\prime}$ & 1626.10 & -0.08 \\
$\mathrm{~A}_{1}^{\prime}$ & 3336.10 & -1.50 \\
$\mathrm{E}^{\prime} \mathrm{E}(\mathrm{s})$ & 5052.60 & -0.40 \\
$\mathrm{E}^{\prime \prime} \mathrm{E}(\mathrm{a})$ & 5052.97 & -0.63
\end{tabular}




\begin{tabular}{|c|c|c|c|}
\hline $\mathrm{E}^{\prime} \mathrm{E}(\mathrm{s})$ & 6012.90 & -1.02 & -2.01 \\
\hline $\mathrm{E}^{\prime \prime} \mathrm{E}(\mathrm{a})$ & 6037.12 & -0.21 & -1.53 \\
\hline $\mathrm{A}_{1}^{\prime}$ & 6520 & -1.21 & -9.40 \\
\hline $\mathrm{A}_{1}^{\prime}$ & 6606.00 & -0.14 & -11.15 \\
\hline $\mathrm{A}_{1}^{\prime} \mathrm{A}(\mathrm{s})$ & 6796.733 & -1.57 & -15.63 \\
\hline $\mathrm{A}_{2}^{\prime \prime} \mathrm{A}(\mathrm{a})$ & 6795.305 & -1.36 & -15.36 \\
\hline $\mathrm{E}^{\prime \prime} \mathrm{E}(\mathrm{a})$ & 6609.66 & -1.01 & \\
\hline $\mathrm{E}^{\prime} \mathrm{E}(\mathrm{s})$ & 6608.833 & -0.90 & \\
\hline $\mathrm{E}^{\prime} \mathrm{E}$ & 6666 & -0.37 & \\
\hline $\mathrm{E}^{\prime \prime} \mathrm{E}(\mathrm{a})$ & 6677.95 & -1.21 & \\
\hline $\mathrm{E}^{\prime} \mathrm{E}(\mathrm{s})$ & 6677.229 & -1.24 & \\
\hline $\mathrm{E}^{\prime \prime} \mathrm{E}(\mathrm{a})$ & 6850.702 & -1.24 & 2.58 \\
\hline $\mathrm{E}^{\prime} \mathrm{E}(\mathrm{s})$ & 6850.195 & -1.32 & 2.47 \\
\hline $\mathrm{E}^{\prime \prime} \mathrm{E}(\mathrm{a})$ & 9738.839 & -2.56 & \\
\hline$E^{\prime} E(s)$ & 9738.15 & -1.70 & \\
\hline $\mathrm{E}^{\prime \prime} \mathrm{E}(\mathrm{a})$ & 9689.722 & -2.89 & \\
\hline $\mathrm{E}^{\prime} \mathrm{E}(\mathrm{s})$ & 9689.84 & -1.87 & \\
\hline $\mathrm{E}^{\prime \prime} \mathrm{E}(\mathrm{a})$ & 9642.323 & -2.58 & -6.96 \\
\hline $\mathrm{E}^{\prime} \mathrm{E}(\mathrm{a})$ & 9639.652 & -2.06 & -7.49 \\
\hline $\mathrm{E}^{\prime \prime} \mathrm{E}(\mathrm{av})$ & 12628.20 & 0.64 & \\
\hline $\mathrm{E}^{\prime} \mathrm{E}(\mathrm{av})$ & 12675.50 & -0.89 & \\
\hline $\mathrm{A}_{2}^{\prime \prime} \mathrm{A}(\mathrm{a})$ & 15447.38 & 0.47 & \\
\hline $\mathrm{A}_{1}^{\prime} \mathrm{A}(\mathrm{s})$ & 15450.82 & -8.16 & \\
\hline $\mathrm{E}^{\prime \prime} \mathrm{E}(\mathrm{a})$ & 15448.70 & -6.94 & \\
\hline $\mathrm{E}^{\prime} \mathrm{E}(\mathrm{s})$ & 15451.19 & -6.92 & \\
\hline $\mathrm{A}_{2}^{\prime \prime} \mathrm{A}(\mathrm{a})$ & 18109.18 & -14.31 & \\
\hline $\mathrm{A}_{1}^{\prime} \mathrm{A}(\mathrm{s})$ & 18109.47 & -6.10 & \\
\hline $\mathrm{E}^{\prime \prime} \mathrm{E}(\mathrm{a})$ & 18107.56 & -15.18 & \\
\hline $\mathrm{E}^{\prime} \mathrm{E}(\mathrm{s})$ & 18109.47 & -9.95 & \\
\hline
\end{tabular}


TABLE V: Vibrational term values of $\mathrm{H}_{2}{ }^{16} \mathrm{O}$ computed $a b$ initio using the same model employed for $\mathrm{NH}_{3}$. Observed from the IUPAC [90].

\begin{tabular}{cccccccc}
\hline \hline$v_{1}$ & $v_{2}$ & $v_{3}$ & obs. & calc. 1 & obs.-calc. & calc. 2 & obs.-calc. \\
\hline 0 & 1 & 0 & 1594.75 & 1595.56 & -0.81 & 1595.18 & -0.44 \\
0 & 2 & 0 & 3151.63 & 3152.98 & -1.35 & 3152.19 & -0.56 \\
1 & 0 & 0 & 3657.05 & 3658.65 & -1.59 & 3658.60 & -1.54 \\
0 & 0 & 1 & 3755.93 & 3757.54 & -1.61 & 3756.60 & -0.67 \\
1 & 1 & 0 & 5234.98 & 5237.36 & -2.38 & 5236.93 & -1.96 \\
0 & 1 & 1 & 5331.27 & 5333.59 & -2.32 & 5332.30 & -1.03 \\
1 & 2 & 0 & 6775.09 & 6777.95 & -2.85 & 6777.11 & -2.02 \\
0 & 2 & 1 & 6871.52 & 6874.30 & -2.78 & 6872.62 & -1.10 \\
2 & 0 & 0 & 7201.54 & 7204.30 & -2.76 & 7204.23 & -2.69 \\
1 & 0 & 1 & 7249.82 & 7252.57 & -2.76 & 7251.59 & -1.77 \\
0 & 0 & 2 & 7445.06 & 7448.13 & -3.08 & 7448.24 & -3.18 \\
2 & 1 & 0 & 8761.58 & 8765.12 & -3.54 & 8764.68 & -3.10 \\
1 & 1 & 1 & 8807.00 & 8810.50 & -3.50 & 8809.17 & -2.17 \\
0 & 1 & 2 & 9000.14 & 9003.91 & -3.77 & 9003.67 & -3.53 \\
2 & 2 & 0 & 10284.36 & 110288.40 & -4.03 & 10287.56 & -3.20 \\
1 & 2 & 1 & 10328.73 & 110332.71 & -3.98 & 10330.99 & -2.26 \\
0 & 2 & 2 & 10521.76 & 110525.97 & -4.21 & 10525.36 & -3.60 \\
3 & 0 & 0 & 10599.69 & 110603.54 & -3.85 & 10603.49 & -3.80 \\
2 & 0 & 1 & 10613.36 & 110617.07 & -3.72 & 10616.07 & -2.71 \\
1 & 0 & 2 & 10868.87 & 110873.12 & -4.24 & 10873.10 & -4.23 \\
0 & 0 & 3 & 11032.40 & 111036.44 & -4.03 & 11035.59 & -3.19 \\
3 & 1 & 0 & 12139.32 & 112144.21 & -4.89 & 12143.80 & -4.48 \\
2 & 1 & 1 & 12151.25 & 112156.03 & -4.78 & 12154.67 & -3.42 \\
1 & 1 & 2 & 12407.66 & 112412.62 & -4.96 & 12412.23 & -4.57
\end{tabular}




\begin{tabular}{|c|c|c|c|c|c|}
\hline 0 & 1 & $\begin{array}{lll}3 & 12565.01 & 112569.73\end{array}$ & -4.73 & 12568.57 & -3.56 \\
\hline 3 & 2 & $\begin{array}{lll}0 & 13640.72 & 113646.23\end{array}$ & -5.51 & 13645.21 & -4.50 \\
\hline 2 & 2 & 113652.65113658 .18 & -5.53 & 13656.47 & -3.81 \\
\hline 4 & 0 & $\begin{array}{llll}0 & 13828.27 & 113834.32\end{array}$ & -6.04 & 13834.28 & -6.01 \\
\hline 3 & 0 & $\begin{array}{ll}1 & 13830.94113836 .85\end{array}$ & -5.92 & 13833.95 & -3.01 \\
\hline 1 & 2 & $2 \quad 13910.89113916 .41$ & -5.52 & 13915.66 & -4.76 \\
\hline 0 & 2 & $\begin{array}{lll}3 & 14066.19 & 114071.42\end{array}$ & -5.23 & 14069.92 & -3.73 \\
\hline 2 & 0 & $2 \quad 14221.16114226 .98$ & -5.82 & 14226.89 & -5.73 \\
\hline 1 & 0 & $\begin{array}{lll}3 & 14318.81 & 114323.88\end{array}$ & -5.07 & 14322.95 & -4.14 \\
\hline 0 & 0 & 414537.50114542 .12 & -4.61 & 14542.31 & -4.81 \\
\hline 4 & 1 & $\begin{array}{lll}0 & 15344.50 & 115352.35\end{array}$ & -7.85 & 15351.93 & -7.42 \\
\hline
\end{tabular}

TABLE VI: Calculated vibrational transition moments of ammonia molecule. All the transitions are from ground state, so freq. $=E_{\mathrm{up}} ; v_{\mathrm{str}}=v_{1}+v_{3}$ is the total stretching excitation; Sym. is the irreducible representation in the $D_{3 h}(M)$ group; int. is the vibrational band intensity in $\mathrm{cm} /$ molecule.

\begin{tabular}{crrrrr}
\hline \hline freq. & int. $v_{\text {str }}$ & $v_{2}$ & $v_{4}$ & Sym. \\
\hline 12619.65 & $1.47 \mathrm{E}-28$ & 3 & 1 & 1 & $\mathrm{E}^{\prime}$ \\
12627.15 & $1.31 \mathrm{E}-28$ & 3 & 3 & 0 & $\mathrm{~A}_{2}^{\prime \prime}$ \\
12628.69 & $1.71 \mathrm{E}-28$ & 4 & 0 & 0 & $\mathrm{~A}_{2}^{\prime \prime}$ \\
12628.85 & $1.98 \mathrm{E}-38$ & 3 & 0 & 1 & $\mathrm{~A}_{1}^{\prime \prime}$ \\
12629.26 & $8.29 \mathrm{E}-28$ & 4 & 0 & 0 & $\mathrm{E}^{\prime}$ \\
12633.02 & $1.50 \mathrm{E}-29$ & 1 & 6 & 2 & $\mathrm{E}^{\prime}$ \\
12642.14 & $8.34 \mathrm{E}-29$ & 3 & 1 & 1 & $\mathrm{~A}_{2}^{\prime \prime}$ \\
12651.06 & $6.26 \mathrm{E}-29$ & 3 & 3 & 0 & $\mathrm{E}^{\prime}$ \\
12661.57 & $1.02 \mathrm{E}-28$ & 1 & 3 & 4 & $\mathrm{~A}_{2}^{\prime \prime}$ \\
12655.96 & $1.83 \mathrm{E}-28$ & 0 & 0 & 8 & $\mathrm{E}^{\prime}$
\end{tabular}




$$
\begin{aligned}
& 12677.15 \text { 7.12E-28 } \quad 4 \quad 0 \quad 0 \quad \mathrm{E}^{\prime} \\
& 12678.37 \text { 2.04E-28 } 22 \quad 6 \quad 0 \quad \mathrm{E}^{\prime} \\
& 12679.10 \quad 2.74 \mathrm{E}-28 \quad 4 \quad 0 \quad 0 \quad \mathrm{~A}_{2}^{\prime \prime} \\
& 12698.93 \quad 3.45 \mathrm{E}-28 \quad 1 \quad 2 \quad 5 \quad \mathrm{E}^{\prime} \\
& 15400.22 \quad 7.64 \mathrm{E}-30 \quad 0 \quad 0 \quad 3 \quad \mathrm{~A}_{2}^{\prime \prime} \\
& 15402.91 \text { 2.61E-31 } 00001 \quad \mathrm{E}^{\prime} \\
& 15407.52 \text { 4.27E-32 } 000000 \text { A } \\
& 15412.47 \text { 2.52E-30 } 0012 \quad 2 \quad \mathrm{~A}_{2}^{\prime \prime}
\end{aligned}
$$

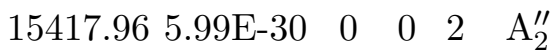

$$
\begin{aligned}
& 15422.55 \text { 1.25E-29 } 00 \begin{array}{llll} 
& 0 & 2 & \mathrm{E}^{\prime}
\end{array} \\
& 15431.20 \quad 7.54 \mathrm{E}-32 \quad 0 \quad 002 \quad \mathrm{E}^{\prime} \\
& 15440.54 \text { 4.92E-30 } 11 \quad 1 \quad 0 \quad \mathrm{~A}_{2}^{\prime \prime} \\
& 15443.00 \text { 1.03E-29 } 0000 \quad \mathrm{E}^{\prime} \\
& 15446.12 \text { 1.31E-29 } 00001 \quad \mathrm{E}^{\prime} \\
& 15448.62 \quad 7.52 \mathrm{E}-29 \quad 0 \quad 0 \quad 0 \quad \mathrm{~A}_{2}^{\prime \prime} \\
& 15452.93 \text { 3.69E-29 } 11 \quad 1 \quad 0 \quad \mathrm{E}^{\prime} \\
& 15457.13 \text { 1.86E-29 } 00001 \quad \mathrm{~A}_{2}^{\prime \prime} \\
& \text { 15458.46 2.62E-29 } 00 \begin{array}{llll} 
& 0 & 2 & \mathrm{E}^{\prime}
\end{array} \\
& 15460.30 \quad 2.01 \mathrm{E}-28 \quad 0 \quad 50 \quad 0 \quad \mathrm{E}^{\prime} \\
& 15461.13 \text { 2.06E-28 } 50 \begin{array}{llll}
0 & 0 & \mathrm{~A}_{2}^{\prime \prime}
\end{array}
\end{aligned}
$$

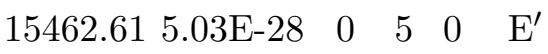

$$
\begin{aligned}
& 15464.40 \text { 1.64E-28 } \quad 0 \quad 0 \quad 2 \quad \mathrm{E}^{\prime} \\
& 15465.75 \text { 7.62E-29 } 00002 \quad \mathrm{E}^{\prime} \\
& 15471.34 \text { 2.08E-30 } 00003 \quad \mathrm{~A}_{2}^{\prime \prime} \\
& \begin{array}{llllll}
15472.54 & 8.27 \mathrm{E}-29 & 2 & 1 & 1 & \mathrm{E}^{\prime}
\end{array} \\
& 15479.57 \text { 6.59E-30 } 000 \begin{array}{llll} 
& 0 & 0 & \mathrm{E}^{\prime}
\end{array} \\
& \text { 15483.25 2.16E-29 } 00 \begin{array}{llll} 
& 0 & 1 & \mathrm{E}^{\prime}
\end{array} \\
& 15484.95 \text { 1.57E-29 } 00 \begin{array}{llll} 
& 0 & 1 & \mathrm{E}^{\prime}
\end{array} \\
& \begin{array}{llllll}
18100.82 & 3.74 \mathrm{E}-29 & 3 & 1 & 0 & \mathrm{E}^{\prime}
\end{array} \\
& \begin{array}{llllll}
18102.36 & 2.77 \mathrm{E}-32 & 1 & 1 & 0 & \mathrm{~A}_{2}^{\prime \prime}
\end{array}
\end{aligned}
$$




$$
\begin{array}{llllll}
18104.85 & 4.05 \mathrm{E}-29 & 3 & 0 & 1 & \mathrm{E}^{\prime} \\
18105.09 & 9.47 \mathrm{E}-31 & 1 & 1 & 0 & \mathrm{~A}_{2}^{\prime \prime} \\
18107.96 & 7.94 \mathrm{E}-31 & 1 & 0 & 2 & \mathrm{~A}_{2}^{\prime \prime} \\
18112.67 & 2.16 \mathrm{E}-30 & 2 & 0 & 2 & \mathrm{E}^{\prime} \\
18118.74 & 3.20 \mathrm{E}-30 & 1 & 0 & 2 & \mathrm{E}^{\prime} \\
18121.44 & 1.08 \mathrm{E}-29 & 1 & 1 & 0 & \mathrm{E}^{\prime} \\
18124.62 & 1.17 \mathrm{E}-28 & 6 & 0 & 0 & \mathrm{E}^{\prime} \\
18126.44 & 9.96 \mathrm{E}-29 & 6 & 0 & 0 & \mathrm{E}^{\prime} \\
18128.48 & 6.89 \mathrm{E}-30 & 0 & 0 & 3 & \mathrm{~A}_{2}^{\prime \prime} \\
18130.57 & 1.05 \mathrm{E}-28 & 6 & 0 & 0 & \mathrm{E}^{\prime} \\
18131.58 & 1.06 \mathrm{E}-28 & 6 & 0 & 0 & \mathrm{~A}_{2}^{\prime \prime} \\
18132.40 & 1.00 \mathrm{E}-28 & 6 & 0 & 0 & \mathrm{E}^{\prime} \\
18133.07 & 1.36 \mathrm{E}-30 & 0 & 2 & 2 & \mathrm{~A}_{2}^{\prime \prime} \\
18136.10 & 4.82 \mathrm{E}-29 & 3 & 1 & 1 & \mathrm{E}^{\prime} \\
18137.51 & 3.37 \mathrm{E}-31 & 0 & 0 & 3 & \mathrm{~A}_{2}^{\prime \prime} \\
18137.77 & 3.57 \mathrm{E}-29 & 3 & 1 & 1 & \mathrm{E}^{\prime} \\
18141.69 & 7.32 \mathrm{E}-30 & 0 & 0 & 1 & \mathrm{~A}_{2}^{\prime \prime} \\
18147.69 & 3.77 \mathrm{E}-30 & 1 & 0 & 2 & \mathrm{E}^{\prime} \\
18150.55 & 7.69 \mathrm{E}-30 & 1 & 0 & 2 & \mathrm{E}^{\prime}
\end{array}
$$

TABLE VII: Vibrational energy levels of the $\mathrm{NH}_{2} \mathrm{D}$ molecule

\begin{tabular}{cccc}
\hline \hline Sym. & obs. & obs-calc $($ this work) & obs-calc $[88]$ \\
\hline A- & 0.41 & 0.00 & 0.01 \\
A & 876.37 & -0.52 & 0.00 \\
A- & 896.56 & -0.38 & 0.00 \\
B+ & 1389.91 & 0.05 & 0.13 \\
B- & 1390.50 & 0.05 & 0.14 \\
A- & 1591 & 0.02 & 0.28
\end{tabular}




\begin{tabular}{cccc}
$\mathrm{A}+$ & 1605.64 & -0.06 & 0.02 \\
$\mathrm{~A}-$ & 2505.9 & -1.24 & 1.26 \\
$\mathrm{~A}+2506.51$ & -1.23 & 1.01 \\
$\mathrm{~A}+3365.24$ & -1.32 & 5.56 \\
$\mathrm{~A}-3367.59$ & -1.27 & 4.29 \\
$\mathrm{~B}+3438.86$ & -0.90 & -0.27 \\
$\mathrm{~B}-3439.03$ & -0.94 & -0.27 \\
\hline \hline
\end{tabular}

TABLE VIII: Vibrational energy levels of the $\mathrm{NHD}_{2}$ molecule

\begin{tabular}{cccc}
\hline \hline Sym. & \multicolumn{3}{c}{ obs. obs-calc $($ this } \\
\hline A- & 0.171 & 0.00 & 0.00 \\
A+ & 810.23 & -0.39 & 0.01 \\
A- & 819.56 & -0.34 & -0.02 \\
A+ & 1233.37 & -0.02 & 0.26 \\
A- & 1235.89 & 0.01 & 0.24 \\
B+ & 1461.79 & 0.06 & 0.22 \\
B- & 1461.99 & 0.03 & 0.21 \\
A+ & 2430.80 & -0.94 & 0.69 \\
A- & 2434.62 & -1.00 & 0.55 \\
B+ & 2559.81 & -1.52 & 1.82 \\
B- & 2559.96 & -1.54 & 1.82 \\
A- & 3404.24 & -1.68 & -2.86 \\
A+ & 3404.32 & -1.45 & -3.03 \\
\hline \hline
\end{tabular}


TABLE IX: Vibrational energy levels of the $\mathrm{ND}_{3}$ molecule

\begin{tabular}{|c|c|c|c|}
\hline Sym & obs. & obs-calc (this work) & lc $[88]$ \\
\hline A2- & 0.053 & 0.00 & 0.00 \\
\hline $\mathrm{A} 1+$ & 745.6 & -0.34 & -0.12 \\
\hline A2- & 749.14 & -0.33 & -0.13 \\
\hline $\mathrm{E}+$ & 1191.49 & 1.00 & 1.23 \\
\hline E- & 1191.56 & 1.00 & 1.23 \\
\hline $\mathrm{A} 1+$ & 1359 & -0.96 & 0.38 \\
\hline A2- & 1429 & -1.63 & -0.60 \\
\hline $\mathrm{A} 1+$ & 1830 & 2.56 & 3.22 \\
\hline A2- & 2106.6 & -0.89 & 0.04 \\
\hline $\mathrm{A} 1+$ & 2359 & 4.01 & \\
\hline A2- & 2359 & 3.63 & \\
\hline $\mathrm{A} 1+$ & 2420.11 & -1.21 & 1.53 \\
\hline A2- & 2420.65 & -1.21 & 1.53 \\
\hline $\mathrm{A} 1+$ & 2482 & 0.54 & 1.42 \\
\hline E- & 2563.91 & -1.79 & 1.95 \\
\hline $\mathrm{E}+$ & 2563.93 & -1.74 & 1.95 \\
\hline A2- & 2876 & 4.08 & 6.04 \\
\hline $\mathrm{A} 1+$ & 3093.01 & -1.23 & 0.97 \\
\hline A2- & 3099.46 & -0.50 & 1.62 \\
\hline $\mathrm{A} 1+$ & 3171.89 & -1.80 & 4.28 \\
\hline A2- & 3175.87 & -1.73 & 3.91 \\
\hline $\mathrm{E}+$ & 3327.94 & -2.07 & 0.14 \\
\hline E- & 3329.56 & -2.10 & 0.12 \\
\hline E+ & 4887.29 & -2.64 & -0.28 \\
\hline E- & 4887.67 & -2.83 & -0.34 \\
\hline E- & 4938.44 & -2.88 & -0.77 \\
\hline $\mathrm{E}+$ & 4938.44 & -2.62 & -0.95 \\
\hline $\mathrm{E}+$ & 5100.66 & -3.39 & 4.42 \\
\hline E- & 5100.66 & -3.40 & 4.40 \\
\hline
\end{tabular}


TABLE X: Vibrational energy levels of the ${ }^{15} \mathrm{NH}_{3}$ molecule

\begin{tabular}{|c|c|c|c|}
\hline \multicolumn{2}{|c|}{ Sym. obs. [91] } & \multicolumn{2}{|c|}{ calc obs - calc } \\
\hline $\mathrm{A}_{2}^{\prime \prime}$ & 0.761 & 0.76 & 0.01 \\
\hline $\mathrm{A}_{1}^{\prime}$ & 928.509 & 929.05 & -0.54 \\
\hline $\mathrm{A}_{2}^{\prime \prime}$ & 962.912 & 963.27 & -0.36 \\
\hline $\mathrm{A}_{1}^{\prime}$ & 1591.236 & 1592.34 & -1.10 \\
\hline $\mathrm{E}^{\prime}$ & 1623.13 & 1623.07 & 0.06 \\
\hline $\mathrm{E}^{\prime \prime}$ & 1624.19 & 1624.12 & 0.07 \\
\hline $\mathrm{A}_{2}^{\prime \prime}$ & 1870.823 & 1871.30 & -0.47 \\
\hline $\mathrm{A}_{1}^{\prime}$ & 2369.274 & 2369.77 & -0.49 \\
\hline $\mathrm{E}^{\prime}$ & 2533.382 & 2534.58 & -1.19 \\
\hline $\mathrm{E}^{\prime \prime}$ & 2577.571 & 2578.32 & -0.75 \\
\hline $\mathrm{A}_{2}^{\prime \prime}$ & 2876.144 & 2876.32 & -0.18 \\
\hline $\mathrm{A}_{1}^{\prime}$ & 3210.614 & 3210.79 & -0.18 \\
\hline $\mathrm{A}_{2}^{\prime \prime}$ & 3212.335 & 3212.49 & -0.15 \\
\hline$E^{\prime}$ & 3234.107 & 3234.23 & -0.12 \\
\hline $\mathrm{E}^{\prime \prime}$ & 3235.504 & 3235.71 & -0.21 \\
\hline $\mathrm{A}_{1}^{\prime}$ & 3333.306 & 3334.75 & -1.44 \\
\hline $\mathrm{A}_{2}^{\prime \prime}$ & 3334.252 & 3335.74 & -1.49 \\
\hline $\mathrm{E}^{\prime}$ & 3435.167 & 3435.62 & -0.45 \\
\hline $\mathrm{E}^{\prime \prime}$ & 3435.54 & 3435.98 & -0.44 \\
\hline $\mathrm{A}_{1}^{\prime}$ & 4288.186 & 4290.16 & -1.98 \\
\hline $\mathrm{A}_{2}^{\prime \prime}$ & 4312.345 & 4314.30 & -1.95 \\
\hline $\mathrm{E}^{\prime}$ & 6546.951 & 6548.99 & -2.03 \\
\hline $\mathrm{E}^{\prime \prime}$ & 6548.56 & 6550.75 & -2.19 \\
\hline $\mathrm{E}^{\prime}$ & 6596.569 & 6597.99 & -1.42 \\
\hline $\mathrm{E}^{\prime \prime}$ & 6597.607 & 6599.33 & -1.72 \\
\hline$E^{\prime}$ & 6664.486 & 6665.52 & -1.03 \\
\hline $\mathrm{E}^{\prime \prime}$ & 6665.48 & 6666.01 & -0.53 \\
\hline
\end{tabular}


TABLE XI: Comparison of the newly analysed band origins around $8000 \mathrm{~cm}^{-1}$ taken from [87] with our calculations

\begin{tabular}{lllr}
\hline \hline \multirow{2}{*}{ sym exp } & \multicolumn{2}{c}{ observed [87] } & obs.-calc. obs.-calc. (our) \\
$\mathrm{v}_{1}+\mathrm{v}_{2}+2 \mathrm{v}_{4}^{2} \mathrm{~s}$ & 7573.282 & 2.6 & 3.88 \\
$\mathrm{v}_{1}+\mathrm{v}_{2}+2 \mathrm{v}_{3}^{3} \mathrm{~s}$ & 7658.485 & 2.2 & -0.47 \\
$\mathrm{v}_{1}+\mathrm{v}_{2}+2 \mathrm{v}_{3}^{3}$ a & 7675.113 & 2.3 & -0.37 \\
$\mathrm{v}_{2}+2 \mathrm{v}_{3}^{2} \mathrm{~s}$ & 7854.539 & 3.0 & -1.58 \\
$\mathrm{v}_{2}+2 \mathrm{v}_{3}^{2} \mathrm{a}$ & 7864.078 & 2.4 & -1.69 \\
\hline \hline
\end{tabular}

\section{CONCLUSION}

In this paper we have achieved the accuracy about $1 \mathrm{~cm}^{-1}$ for the levels up to $7000 \mathrm{~cm}^{-1}$ given in the comprehensive compilation of experimental levels [10] and an accuracy between 2 to $10 \mathrm{~cm}^{-1}$ for levels up to $18000 \mathrm{~cm}^{-1}$ measured by Lehmann and Coy [20]. This $a b$ initio PES should serve as an excellent starting point for a semi-empirical fit to provide much closer line positions with an accuracy much closer to experimental in both infrared and visible regions.

We also estimate the dissociation energy of $\mathrm{NH}_{3}$ by two independent theoretical procedures and with significantly improved accuracy compared to previous theoretical determinations; however, there is a discrepancy with experiment which requires futher investigation. The paper provides a step towards a global, high-accuracy ab initio PES of ammonia. Our work should also help to pave the way towards the to observation and analysis of the predissociation spectra of $\mathrm{NH}_{3}$ analogous to what could have been achieved for water, only, up until now [92-95].

For the present study the availability of ab initio results for water at various level of theory (i.e., including only some of the components discussed in section II A or using smaller basis sets) including the very accurate one from refs. [25, 92, 96] proved very useful; in particular, we confirmed that use of analoguous levels of theory for water and ammonia leads to similar errors in rovibrational energy levels; we are therefore confident that very accurate results - 
similar in quality to the ones for water of ref. [25] - can be obtained for ammonia as well as for other 10 electron molecules, such as methane. The computationally more onerous step for future calculations is extension to the larger aug-cc-pV6Z basis set, although the use of explicitly-correlated methods and the cc-pV5Z-F12 basis set may provide a valid, cheaper alternative. It will also be necessary to consider relativistic corrections based on the Breit-Coulomb Hamiltonian, quantum electrodynamics corrections as well as a more extensive treatment of nonadiabatic correction such as the one used by Huang et al. [14]. It is expected that ones these corrections are implemented accuracies of the order of $0.1 \mathrm{~cm}^{-1}$ should be achievable $a b$ initio for excited rotation-vibration levels.

\section{ACKNOWLEDGEMENT}

This work was supported by the ERC Advanced Investigator Project 267219, the UK Natural Environment Research Council and the Russian Fund for Fundamental Studies. The State Project IAP RAS No. 0035-2014-009 is acknowledged by RIO, AAK, and NFZ.

[1] J. W. Erisman, J. N. Galloway, S. Seitzinger, A. Bleeker, N. B. Dise, A. M. R. Petrescu, A. M. Leach, and W. de Vries, Phil. Trans. Royal Soc. London B 368 (2013).

[2] K. von Bobrutzki, C. F. Braban, D. Famulari, S. K. Jones, T. Blackall, T. E. L. Smith, M. Blom, H. Coe, M. Gallagher, M. Ghalaieny, et al., Atmos. Meas. Tech. 3, 91 (2010).

[3] P. W. Lucas, C. G. Tinney, B. Burningham, S. K. Leggett, D. J. Pinfield, R. Smart, H. R. A. Jones, F. Marocco, R. J. Barber, S. N. Yurchenko, et al., Mon. Not. R. Astr. Soc. 408, L56 (2010).

[4] S. K. Leggett, C. V. Morley, M. S. Marley, and D. Saumon, Astrophys. J. 799, 37 (2015).

[5] J. P. Beaulieu, G. Tinetti, D. Kipping, I. Ribas, R. J. Barber, J. Y.-K. Cho, I. Polichtchouk, J. Tennysson, S. N. Yurchenko, C. A. Griffith, et al., Astrophys. J. 731, 16 (2011).

[6] N. F. Zobov, S. V. Shirin, R. I. Ovsyannikov, O. L. Polyansky, S. N. Yurchenko, R. J. Barber, J. Tennyson, R. Hargreaves, and P. Bernath, J. Mol. Spectrosc. 269, 104 (2011).

[7] R. J. Hargreaves, G. Li, and P. F. Bernath, J. Quant. Spectrosc. Radiat. Transf. 113, 670 (2012). 
[8] R. J. Hargreaves, G. Li, and P. F. Bernath, Astrophys. J. 735, 111 (2012).

[9] E. J. Barton, S. N. Yurchenko, J. Tennyson, S. Clausen, and A. Fateev, J. Quant. Spectrosc. Radiat. Transf. 167, 126 (2015).

[10] A. R. Al Derzi, T. Furtenbacher, S. N. Yurchenko, J. Tennyson, and A. G. Császár, J. Quant. Spectrosc. Radiat. Transf. 161, 117 (2015).

[11] T. Rajamäki, A. Miani, and L. Halonen, J. Chem. Phys. 118, 10929 (2003).

[12] T. Rajamäki, M. Kállay, T. Noga, P. Valiron, and L. Halonen, Mol. Phys. 102, 2297 (2004).

[13] X. Huang, D. W. Schwenke, and T. J. Lee, J. Chem. Phys. 129, 214304 (2008).

[14] X. Huang, D. W. Schwenke, and T. J. Lee, J. Chem. Phys. 134, 044320 (2011).

[15] X. Huang, D. W. Schwenke, and T. J. Lee, J. Chem. Phys. 134, 044321 (2011).

[16] S. N. Yurchenko, R. J. Barber, A. Yachmenev, W. Thiel, P. Jensen, and J. Tennyson, J. Phys. Chem. A 113, 11845 (2009).

[17] S. N. Yurchenko, R. J. Barber, and J. Tennyson, Mon. Not. R. Astr. Soc. 413, 1828 (2011).

[18] S. N. Yurchenko, R. J. Barber, J. Tennyson, W. Thiel, and P. Jensen, J. Mol. Spectrosc. 268, 123 (2011).

[19] S. L. Coy and K. K. Lehmann, J. Chem. Phys. 84, 5239 (1986).

[20] K. K. Lehmann and S. L. Coy, J. Chem. Soc. Faraday Trans. II 84, 1389 (1988).

[21] C. Sousa-Silva, N. Hesketh, S. N. Yurchenko, C. Hill, and J. Tennyson, J. Quant. Spectrosc. Radiat. Transf. 142, 66 (2014).

[22] R. Marquardt, K. Sagui, J. Zheng, W. Thiel, D. Luckhaus, S. Yurchenko, F. Mariotti, and M. Quack, J. Phys. Chem. A 117, 7502 (2013).

[23] S. Yurchenko, P. Jensen, and W. Thiel, J. Chem. Phys. 71, 281 (2004).

[24] S. Yurchenko, P. Jensen, and W. Thiel, J. Chem. Phys. 90, 333 (2010).

[25] O. L. Polyansky, R. I. Ovsyannikov, A. A. Kyuberis, L. Lodi, J. Tennyson, and N. F. Zobov, J. Phys. Chem. A 117, 96339643 (2013).

[26] A. Kyuberis, L. Lodi, N. Zobov, and O. Polyansky, J. Mol. Spectrosc. 316, 38 (2015).

[27] P. Szalay, T. Müller, G. Gidofalvi, H. Lischka, and R. Shepard, Chemical Review 112, 108 (2012).

[28] T. H. Dunning, Jr, Journal of Chemical Physics 90, 1007 (1989).

[29] D. E. Woon and T. H. Dunning Jr., Journal of Chemical Physics 103, 4572 (1995).

[30] K. A. Peterson and T. H. Dunning Jr. , Journal of Chemical Physics 117, 10548 (13 pages) 
(2002).

[31] D. Feller, J. Chem. Phys. 138, 074103 (2013).

[32] D. Feller, K. A. Peterson, and J. G. Hill, J. Chem. Phys. 135, 044102 (2011).

[33] K. A. Peterson, D. Feller, and D. A. Dixon, Theor. Chem. Acc. 131, 1079 (2012).

[34] M. Pavanello, L. Adamowicz, A. Alijah, N. F. Zobov, I. I. Mizus, O. L. Polyansky, J. Tennyson, T. Szidarovszky, A. G. Császár, M. Berg, et al., Phys. Rev. Lett. 108, 023002 (2012).

[35] M. Pavanello, L. Adamowicz, A. Alijah, N. F. Zobov, I. I. Mizus, O. L. Polyansky, J. Tennyson, T. Szidarovszky, and A. G. Császár, J. Chem. Phys. 136, 184303 (2012).

[36] X. Huang, R. S. Freedman, S. A. Tashkun, D. W. Schwenke, and T. J. Lee, J. Quant. Spectrosc. Radiat. Transf. 130, 134 (2013).

[37] L. Lodi, J. Tennyson, and O. L. Polyansky, J. Chem. Phys. 135, 034113 (2011).

[38] G. Tarczay, A. G. Császár, W. Klopper, and H. M. Quiney, Molecular Physics 99, 1769 (2001).

[39] A. G. Császár, J. S. Kain, O. L. Polyansky, N. F. Zobov, and J. Tennyson, Chem. Phys. Lett. 293, 317 (1998), erratum 312, 613-616 (1999).

[40] P. Pyykkö, Chem. Rev. 112, 371 (2012).

[41] J. Autschbach, J. Chem. Phys. 136, 150902 (2012).

[42] H. M. Quiney, P. Barletta, G. Tarczay, A. G. Császár, O. L. Polyansky, and J. Tennyson, Chem. Phys. Lett. 344, 413 (2001).

[43] P. Pyykkö, Adv. Quantum Chem. 11, 353 (1978).

[44] L. Lodi, O. L. Polyansky, A. A. J. Tennyson, and N. F. Zobov, Phys. Rev. A 89, 032505 (2014).

[45] P. Pyykkö, K. G. Dyall, A. G. Császár, G. Tarczay, O. L. Polyansky, and J. Tennyson, Phys. Rev. A 63, 024502 (2001).

[46] O. L. Polyansky and J. Tennyson, J. Chem. Phys. 110, 5056 (1999).

[47] P. R. Bunker and R. E. Moss, J. Mol. Spectrosc. 80, 217 (1980).

[48] D. W. Schwenke, J. Phys. Chem. A 105, 2352 (2001).

[49] S. P. A. Sauer and J. F. Ogilvie, J. Phys. Chem. 98, 8617 (1994).

[50] J. F. Ogilvie, J. Oddershede, and S. P. A. Sauer, Adv. Chem. Phys. 111, 475 (2000).

[51] N. F. Zobov, S. V. Shirin, L. Lodi, B. C. Silva, J. Tennyson, A. G. Császár, and O. L. Polyansky, Chem. Phys. Lett. 507, 48 (2011).

[52] C. M. Marian, Rev. Comp. Chem. 17, 99 (2001). 
[53] C. M. Marian, WIREs Comput. Mol. Sci. 2, 187 (2012).

[54] R. J. Gdanitz and R. Ahlrichs, Chem. Phys. Lett. 143, 413 (1988).

[55] P. G. Szalay and R. J. Bartlett, J. Chem. Phys. 103, 3600 (1995).

[56] H.-J. Werner and P. J. Knowles, J. Chem. Phys. 89, 5803 (1988).

[57] G. K. K. R. Shamasundar and H.-J. Werner, J. Chem. Phys. 135, 054101 (2011).

[58] D. I. Lyakh, V. F. L. M. Musiał, and R. J. Bartlett, Chem. Rev. 112, 182 (2012).

[59] Z. Rolik and M. Kállay, J. Chem. Phys. 141, 134112 (2014).

[60] P. Barker, S. M. Purcell, P. Douglas, P. Barletta, N. Coppendale, C. Maher-McWilliams, and J. Tennyson, Faraday Discuss. 142, 175 (2009).

[61] K. Sung, L. R. Brown, X. Huang, D. W. Schwenke, T. J. Lee, S. L. Coy, and K. K. Lehmann, J. Quant. Spectrosc. Radiat. Transfer 113, 1066 (2012).

[62] P. Celani and H.-J. Werner, J. Chem. Phys. 112, 5546 (2000).

[63] S. Yurchenko, J. Zheng, H. Lin, P. Jensen, and W. Thiel, J. Chem. Phys. 123, 134308 (2005).

[64] H. Lin, W. Thiel, S. Yurchenko, M. Carvajal, and P. Jensen, J. Chem. Phys. 117, 11265 (2002).

[65] S. N. Yurchenko, W. Thiel, and P. Jensen, J. Mol. Spectrosc. 240, 174 (2006).

[66] S. N. Yurchenko, P. R. Bunker, and P. Jensen, J. Molec. Struct. (THEOCHEM) 742, 43 (2005).

[67] R. I. Ovsyannikov, W. Thiel, S. N. Yurchenko, M. Carvajal, and P. Jensen, J. Mol. Spectrosc. 252, 121 (2008).

[68] S. N. Yurchenko, W. Thiel, M. Carvajal, and P. Jensen, Contemp. Phys. 346, 146 (2008).

[69] D. S. Underwood, J. Tennyson, and S. N. Yurchenko, Phys. Chem. Chem. Phys. 15, 10118 (2013).

[70] O. V. Boyarkin, M. A. Koshelev, O. Aseev, P. Maksyutenko, T. R. Rizzo, N. F. Zobov, L. Lodi, J. Tennyson, and O. L. Polyansky, Chem. Phys. Lett. 568-569, 14 (2013).

[71] D. K. Bohme, R. S. Hemsworth, and H. W. Rundle, J. Chem. Phys. 59, 77 (1973).

[72] S. T. Gibson, J. P. Greene, and J. Berkowitz, J. Chem. Phys. 83, 4319 (1985).

[73] F. Qi, L. Sheng, Y. Zhang, S. Yu, and W.-K. Li, Chem. Phys. Lett. 234, 450 (1995).

[74] D. H. Mordaunt, R. N. Dixon, and M. N. R. Ashfold, J. Chem. Phys. 104, 6472 (1996).

[75] P. J. Knowles, C. Hampel, and H.-J. Werner, J. Chem. Phys. 99, 5219 (1993).

[76] P. J. Knowles, C. Hampel, and H.-J. Werner, J. Chem. Phys. 112, 3106 (2000). 
[77] H.-J. Werner, P. J. Knowles, G. Knizia, F. R. Manby, M. Schütz, P. Celani, T. Korona, R. Lindh, A. Mitrushenkov, G. Rauhut, et al., Molpro, version 2012.1, a package of ab initio programs (2012), see www.molpro.net.

[78] MRCC, MRCC, a string-based quantum chemical program suite written by M. Kállay. See www.mrcc.hu.

[79] M. Kállay and P. R. Surján, J. Chem. Phys. 115, 2945 (2001).

[80] M. Reiher, Theoretical Chemistry Accounts 116, 241 (2006).

[81] J. Stanton, J. Gauss, M. Harding, P. Szalay, A. Auer, R. Bartlett, U. Benedikt, C. Berger, D. Bernholdt, Y. Bomble, et al., Cfour, a quantum chemical program package, For the current version, see http://www. cfour. de (2009).

[82] J. Gauss, A. Tajti, M. Kállay, J. F. Stanton, and P. G. Szalay, J. Chem. Phys. 125, 144111 (2006).

[83] J. Demaison, L. Margulès, and J. E. Boggs, Phys. Chem. Chem. Phys. 5, 3359 (2003).

[84] A. Yachmenev and S. N. Yurchenko, J. Chem. Phys. 143, 014105 (2015).

[85] T. Furtenbacher, A. G. Császár, and J. Tennyson, J. Mol. Spectrosc. 245, 115 (2007).

[86] T. Furtenbacher and A. G. Császár, J. Quant. Spectrosc. Radiat. Transf. 113, 929 (2012).

[87] E. J. Barton, S. N. Yurchenko, and J. Tennyson, J. Mol. Spectrosc. p. (in preparation) (2016).

[88] R. Marquardt, K. Sagui, J. Zheng, W. Thiel, D. Luckhaus, S. Yurchenko, F. Mariotti, and M. Quack, J. Phys. Chem. A 117, 7502 (2013).

[89] S. N. Yurchenko, J. Zheng, H. Lin, P. Jensen, and W. Thiel, J. Chem. Phys. 123, 134308 (2005).

[90] J. Tennyson, P. F. Bernath, L. R. Brown, A. Campargue, M. R. Carleer, A. G. Császár, L. Daumont, R. R. Gamache, J. T. Hodges, O. V. Naumenko, et al., J. Quant. Spectrosc. Radiat. Transf. 117, 29 (2013).

[91] S. N. Yurchenko, J. Quant. Spectrosc. Radiat. Transf. 152, 28 (2015).

[92] M. Grechko, O. V. Boyarkin, T. R. Rizzo, P. Maksyutenko, N. F. Zobov, S. Shirin, L. Lodi, J. Tennyson, A. G. Császár, and O. L. Polyansky, J. Chem. Phys. 131, 221105 (2009).

[93] A. G. Császár, E. Mátyus, L. Lodi, N. F. Zobov, S. V. Shirin, O. L. Polyansky, and J. Tennyson, J. Quant. Spectrosc. Radiat. Transf. 111, 1043 (2010).

[94] P. Maksyutenko, N. F. Zobov, S. V. Shirin, O. L. Polyansky, J. S. Muenter, T. R. Rizzo, and O. V. Boyarkin, J. Chem. Phys. 126, 241101 (2007). 
[95] M. Grechko, P. Maksyutenko, N. F. Zobov, S. V. Shirin, O. L. Polyansky, T. R. Rizzo, and O. V. Boyarkin, J. Phys. Chem. A 112, 10539 (2008).

[96] D. S. Makarov, M. A. Koshelev, N. F. Zobov, and O. V. Boyarkin, Chem. Phys. Lett. 627, $73(2015)$. 